\title{
SAN MARTIN y los Revolucionarios Peruanos
}

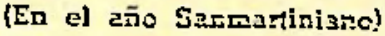

POI GUSTAVO PONS MUZZO

Honrado por la Facultad para traer a las páginas de "LETRAS", la palabra del Claustro con motivo de conmemorarse el segundo centenario del fallecimiento del Libertador don losé de San Martín, he escogido como tema para rendir homenaje al Gran Capitán de los Andes, el de las relaciones que tuvo con los revolucionarios peruanos, y en especial con don tose de la Riva Agutero, en su tarea previa de sublevar moralmente al paissecrear delantemand/unSestado de opinión favorable a la invasión libertadora y preparar los recursos del país de manera que se asegurara el éxito de la empresa.

La Guerra de la Independencia fué un movimiento sclidario de todos los pueblos de América, que por encima de los intereses nācionales, perseguía una finalidad continental. Desde los momentos iniciales, cuando los Precursores dieron la idea y señalaron el rumbo de la emancipación política, se observa este carácter americano del movimiento. Miranda, el Gran Precursor, dirició desde los primeros instantes sus esfuerzos a conseguir la independencia de todo el Continente. Para él, su patria era América. Es por eso que desde el estallido inicial el esfuerzo aislado careció de importancia, y sólo tuvo significación cuando enlazó sus fuerzas dentro del movimiento general que tuvo por norte la emancipación de todas las colonias. 
Interesañe es constatir la presoncia de este esfuerzo común. En los diversos estailidos nacionales de lecs y 1810 y que continuaron por varios afios, sə nota la intevención de personas oriundias de otros lugares de América pero que luchaban por la causa común. Asi por ejempic, al producirse en México en 1808 los primeros intentos revolucionarics, se encuentra parlicipancio de ellos el religioso limeño iray Melchor de Talamantes. A! instalarse en Quito en 1809 la Junla de Gobiemo, su Secretario es el peruano Rodríguez de Quiroga. En Ve nezuela aparece el peruano José de Sala y Bussy al lado de Miranda, formz parte del primer Congreso venezolano, contribuye a proclamar su irdecendencia en lol y parlicipa en el diseño de su primera bandera racional. En Chile colabera desdo los primeros momentos con la Junta de 1810, el petuano fuan Eraña, quion pocteriomente elaborara un "Plan de Gobieno", gue puede considerarse como la expresión teórica de $10 \%$ ideales revolucturarios. In Buenos Aires se encuentra la participación de 5 peruanos: el genetal Alvarez Thomas, ol jurisla losé Darregueyra y los hermanos Toribio, losé y Francisco Luzuriaga. Alvarez Thomas le tocí nesteriormente cjobemar las Provincias Unidas del Río de la Flata, como Director Supremo, en los momentos más críticos de la guera, de riayo dé 1815 a abril de 1816, cuando la ofensiva realisiz triunfaba en todo el Continente, y a Darregueyra formar parte

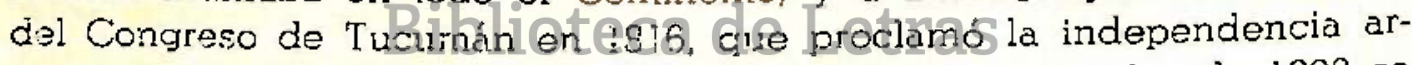
gentina. En el movimionte pereanceldesclentsenños inciales de 1808 se nota la participación de argentinos, altoperuanos, chilenos, elc. Este cárácter de estuerzo sclidario de! movimiento nos explica porqué, al instalarse en 1822 el primer Congreso peruano, de los 71 diputados que lo integraban 60 eran racidos en el Perí y 11 en otros lugares de América española (1).

El esfuerzo comín y la colaboración recíproca, que fué de individuos en los primeros momentos, después se volvió de ejércitos cuando la guerra tomó cuerpo y dirección definida por obra de caudillos geniales. Causas históricas y sociológicas nos dicen porqué los extremos del Continente, la Capitanía General de Venezuela y la Audiencia de Buenos Aires, se convirtieron en los focos de la acción ofensiva de la

(1) Estos hispanoamericanns eran: Don Miguel Tenorio, de Popayáni don Ignacio Alcázar, de Carta!na; don Francisco Argo's, de Cartajena; don Joaquín Paredes, de Quito; don Ignacio Ortíz de Zevallos, de Quito; don José La Mar, de Cuenca; don José Crespo, de Cuence; don José Olmedo, de Guayaquil; don Ántonio Podilla, de Chuquisaca; don Jerúnimo de Agüero, de Valdivia; don Tomás Forcada, de Tu. cumán; don Niguel Otero, de ialta y don Felise Antonio Alvarado, de Buenos Aires. 
Revolución. Oiras causas nos dicen porqué Venezuela se volvió campo cruento de la guerra y España pudo enviar constantemente refuerzos a sofocar la insurrección, lo que no pudo hacer con Buenos Aires por su situación geográiica aislada. Sin enemigos que combatir dentro de sus fronteras, pero amenazada por el poderío español existente más allá de ellas, la revolución argentina vió desde los primeros momentos ka necesidad de expandirse y contribuír a la liberación de las colonias aledañas como una medida de defensa propia (2). Su direccićn era el Perú, pero no por el camino de Charcas, sino por el que le señaló el genio de San Martín y que condujo a la revolución al triunto.

Vencida la Revolución en su primera etapa (1810-1815), (a excepción de Buenos Aires), debido a que no contaba con ejércitos disciplit nados y técnicamente preparados y conducidos, ni con un plan de guerra definido, el genio de San Martín sería el que la conduciría al triunfo con ese ejército de inmortales que preparó en le Región de Cuyo. A partir de !317, la Revolución entracen la etapa del triunfo final, por modio del esfuerzo cornin y la colaboración recíproca. Un ejército argentino-chileno realiza la liberación de Chile en 1817-18; un ejército venezolano-graradino la de Jueva Granada en 1819; un ejército venezulano apoyado por Nueva Granada realiza la liberación de Venezuela en 1821; otro ejórcito formado por hombres de los dos corrientes libertadoras de Américe (peruanos, argentinos, venezolanos y colombianos) realiza la liberación del Ecuadorem 1822, enlosecampos de Pichincha; otro ejército peruano-colombiano realizará en 1825 la liberación del Alto $\mathrm{Pe}$ rú. Y el Perú, por haber sido la colonia más poderosa de España en América y por su situación geográfica especial, necesitó la confluencia de las dos corriertes libeitadoras de América, no sólo para libertarlo, sino para libertar a toda América, porque el Perú armado en poder del Rey de España era una amenaza constante y dividía las fuerzas libertadoras continentales. Su destino continental fué ese: ser el lugar de fusión de los esfuerzos comunes para que se dieran en nuestro suelo las batallas decisivas de la independencia americana. La venida de San Martín al Perú, definió el carácter ofensivo de la guerra y contribuyó decisivamente al triunfo definitivo. Fué él quien empezó a hacer retroceder a las fuerzas realistas desde los campos de Chacabuco hasta encerrarlas finalmente en los Andes del Perú.

(2) Expediciones al Alto y Bajo Perú, de Balcárce en 1810-11; de Belgrano en 1812.13; de Rondeau en 1815. 
Antes de seguir adelānte es necesario esclarecer otro punto importanie: el porqué el Ferú no contribuyó desde los primeros momentos a la lucha, al igua! que las demtás colonias.

Sabemos que fué entre 1809 y 1810 , al impuiso de luerzas intrínsecas y de infiuencias externas, cuando todas las coionias se insurreccionaron y al ainparo de un fingido fidelismo al monarca cautivo, formaron Juntas de Gobierno proclamando el principio del gobierno propio. Sin embargo fué el Perú la única colonia que no siguió el mismo ritmo de sus hermanos de América y aparece ante la historia como la únia que no trajo por tierra a las autoridades españolas existentes, dejando de concurrir --aparentemente- desde el principio a la lucha. Esta actitud del Ferú no significa, de ninguna manera, una excepción en el desarzollo general de los acontecimientos. No puede sinificar que el Perú carecía de emoción retolucionaria y de deseo de independencia. Causas históricás debidamente estudiadas han esclarecido esta situación. Allí están los esfuerzos hechos desde los primeros momentos por prominentes personaies del Virreinato para considerar la situación frente a lo ocurrido en España por la invasión francesa de 1808; tales las reunicnes secretas tenidas en la Escuela de Medicina de San Fernando y en otros lugares, como la casa de los Padres de San Pedro. La anécdoía recogida al respecto por don José Antonio de Lavalle es muy significativa (3) Pás' como también lō son las versiones recogidas lustros más tarde por el historiador chileno Benjamín Vicuña Macko"Jorge Puccinelli Converso"

(3) "Supo Abascol" que en la celda dol Padre Méndez, do la Congregación del Oratorio (*). se reunian todas las noches a conspirar, algunas persones visibles y res. petables dei pais, acmo el Pacie Currinin, de la misma Conparegación, el Conde de la Vega del Ren; don Manuel Pérez de Tudela, don José de la Riva Aqüero y otros igualmente inolensivos. No teniendo por una parte nada de conspiradores de la laya. pero no querinedo por otra çun tales rouniones se fomentasen, tomó para disolverlas, la siguiente garciosa providencia. Ordenó que una noche se aposlase en la portería de San Pedro, el capitán de su guardia de a caballo don Joaguin de Espolavieja, con una linterna y dos soldados. Así se hizo, y amedida que los conjurados salian. poníales don Jeaquín su linterna en la cara y reconicióndoles les decia: "Señor iai su Excelencia el Señor Virrey me ho encargado que diga a Ud. do su parte, gue le desea que pase muy buena noche". "nútil es decir, que esa fuć la última en qua se reunieron los conjurados."- De "Aboscal, el Marcúés de la Concordiar", en "Estudios Históricos", por José Antonio de Lavalle-_ Lima 1935., Páog. 406.

(*) Se trala de don Tomás Méndez Lachica, perteneciente a la Congregación del Oratorio de San Felipe, la sue funcionaba en el local de San Pedro. El Padre Méndez Lachica, tormó parte del primer Congreso Constituyente de 1822, instalado por San líartín, como representante por Huamaniza. 
nna (4). Allí están también la conspiración de 1809 fraguada entre otros, por el español Antonio María Pardo y el criollo Mateo Silva, con el objeto de clbtener del Virrey Abascal un Cabildo Abierto para instalar una Junta de Gobierno a insitación de la que se había formado en España y de las que se acababan de formar en La Paz, Chuquisaca y Quito. Allí están también la conspiración abortada el 18 de setiembre de 1810, en la que fueron presos el presbítero Anahóriz que pertenecía a las sociedades secretas de Cádiz y Buenos Aires (5), el abogado Saravia, el cura de San Sebastián, Tagle, los comerciantes Minondo y López, el italiano Boqui, el editor Guillermo del Río y otros. En el terreno de las conspiraciones armadas tenemos la de Francisco Antonio de Zela, en Tacna en 181 i; la de José Crespo y' Castillo en Huánuco en 1812. la segunda revolución de Tacna en 1813, y finalmente la gran revolución de Pumacahua, Mariano Melgar y los hermanos Angulo

(1) "Reuníanse éstos, bajo cierto sigilo, en una de las salas del Coleơio de San Fernazcio, recién fundado por Abascal, con la cooperación do la facultad médica y paríicularmente de Unánue, y ahí se entregaban a tazonar sobre los destinos intrediatos de América, en vista de los acontecimientos que se sucedían en Europa; y reflexionaban ya sobre los gobiernos que deberían adoptarse en las colonias, en el caso de un transtcrno en el de la metrópoli, ya sobre los derechos que como hombres y ciudadanos tenían a la participación de los privilegios de los peninsulares en la administración pública y en la misma sociedad, o ya, en fin. scbre los justas quejas de los americanos contra las abusos de los gibiernos coloniales y de la autoridad ceniral".

"Un oido inoportuno Jy aleve había escuche do osin embargo, estos coloquios, y Abascal recibió con sorpresa un denuncio que le pintaba como conspiradores, a muchos de los mús altos empleados dal Virreynato, confidentes algunos de su política y todos personas altamente caracterizadas en el país. Más haciendo uso de su alta prudencia, el Virrey se limitó a manifestar privadamente su frialdad y su sorpresa a cada uno de los acusados; y esta conducta hizo en ellos tal impresión que atrajo a los más susceptibles o a los más tímides un resultado funesto".- Benjamín Vicuña Mackenna.- "La Revolución de la Independencia del Perú".- Lima, 1924.Pág. 78.

(5) "Al presbítero Ramón Eduardo Anchóriz, natural de Buenos Aires, lo encontramos en Lima, desempeñando el cargo de mayordomo del arzobispado y reuniendo en su habitación una Soriedad secreta, jue fué uno de los primeros centros de actividades revolucionarias del Perú. Formaba parte del mismo oiro inquieto àrgentino, José Antonio Mirrlla. Pertenecía también a dicho centro José Boqui, portador de una rica custodia a Buenos Aires en la época de las invasiones y que pudo ser también transmisor de inquietudes revolucionarias. Abascal supo con su habilidad anular lo strabajos revolucionarios y detener a los promotores. Más el núcleo resurgiría después con las actividades de Riva Agüero y la instalación de la Sociedad secreta limeña".- "Historia de la Nación Argentina".- Buenos Aires, 1941.Vol V. segundx sección.- Pág. 220. 
en 1814-15, que sublevó Arequipa, Cusco, Huamanga, Puno y gran parte del Aito Perú, pretendiendo enlazét sus fuerzas con la rovciución argentina, $y$ que significa el esfuerzo más notable que hicicron nuestros antepasados para obtener la independencia del país por sí solos.

El exfuerzo de los revolucionarios peruanos por seguir el mismo. ritmo de sus hermanos de Arnérica no fuvo los resuitados esperados, porquie aquí en el Perú, por ser la colonia mús poderosa de España en América, estaba también el mayor poder represivo de las fuerzas realistas, aumentado por la capacidad y sagacidad inciscultible doj Virrey Abascal, que supo aprovechar inteligentemente los recursos del rico Virreinato y prepararlo para la resistencia y la ofeneiva. Frente a ese poder fueron nulos: todos los eśluerzos hechos por los revolucionarios peruanos, y anies bien, Abascal tomó la ofensiva y destruyó a la revolución chilena, alioperuana y auiteña, $y$ mantuvo en jagne a la revolución argentina, que obedeciendo a un impulso natural, $y$ sin enemigos que combatir dentro de su ternitorio, hacta esfueizos por llegar a! Perú a través de la región de Chafcas. Causas históricas debidemente ositudiadas han esclarecido esta situación del perú en el pancrama de la Revolución y la han justificado. Para nosotros es halacüerio trascribir la opinión del gran historiador don Bartolomé Mitre, quien al respecio dice lo siguiente: "Es un hecho que la historia debe consignar, que si el Perú no concurrió desde el principio a la lucha, no es porque le faltasen a todos sus hijos elantiels de la mápendencia y fortaleza de sacrificio, ni porque dejasent de nohé dos rredios a su alcance para sacudir el yugo que los oprimía. El Perú iuvo también sus insurrecciones, que respondieron a la insurrección general, pero fueron solocadas como casi todas las que estallaron durante los primeros culatro años. muriendo sus autores en los calabozos, en los cadalsos o en los compos de batalla. Esto quebrantó sus fuerzas revolucionarias, harto débiles por la falta de cohesión y por el poder realista incontrastable que las anulaba, y de aquí que el Perú sólo pudo ser libertado por el auxilio extraño". (6).

Derrotados los revolucionarios peruanos en los campos de batalla. se dedicaron a la labor subversiva interna con el objelo de mantener vivo el espíritu revolucionario. Lima fué el centro de esta agitación y su principal caudillo don. José de la Riva Agüiero. La labor de este

(6) Bartolomé Mitra-- "Historia de San Marlín y de la Emancipación Sudamericana.Cap. XXV, parte III. 
grupo en el que se encontraba don Francisco de Paula Quirós, don Fernando López Aladena, Remigio Silva, el Conde de la Vega del Ren, don José Grejorio Paredes, el cura Tagle, don Gerónimo Espinosa, don Josś Peral, el padre Carrión, don Mateo Áranda, don Manuel Pérez de Tudela, don Francisco Colmenares y otros; fué de vital importancia $y$ presió grandes servicios a la Expedición Libertadora de San Martín. "Baio la inspiración de Riva Agüero - dice Vicuña Mackenna- comenzaron a iliniarse clubs secretos que celebraban alternativamente sus sesicnes, ya en la misina casa de su caudillo, en el barrio de Saria Teresa, y i en la del Conde de la Vega, en la vecindad de San Pedro, - ya en localidades secrelas que alquilaban en los suburbios con estos propósitcs. Froponíanse los afiliados, ccmo fin principal, el ganarse prosélitos en todas las cièses, el circular noticias alarmantes, el propalar ideas nuevas e invasoras, y más que todo, el despopularizar la administracién vigente y crearle dificultades de toslo género para embarazar sus aclivas medidas contra al rebelión creciente de les otros países". (7).

El grupo de Riva Agüero y los ciue le seguían no se proponían hacer la revolución con sus propias fuerzas. La experiencia vivida desde el ano 10 les había demostrado lo impracticable de tal empresa. Su labor era subversiva, por el momento, esperando la colaboración qua debía venir de más allá de las fronteas del Virreinato. Sólo cuando se enteraron de que San Varitín formaba en Cuyo un ejército para libertar Chile, iniciaron contacio con e? Gran Capíńn, instán-

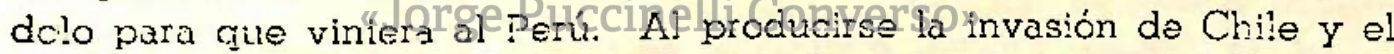
triunfo de Chacabuco, el deseo de qua San Martín viniera al Perá fué más intenso. En el folleto que escribió Riva Agüero en 1816, en Lima, y que fús publicado en 1818 en Buenos Aires, en la "Tntrod:cción". escrita probablemente en 1817, se habla ya de la victoria conesuida por San Martín en Chile y del júbilo y satisfacción con que verían los peruanos la próxima llegada de un ejército y escuadra de sus hermanos del Río de la Plata. (8).

(7) Vicuña Máakenna- Ob. cit.- Pág. 98.

(8) "Los sucesos azaecidos posieriormenle a la émosa cute comprende este escrilo, prueban hásta la evidencia la solidez de sus aserciones. La vuelta al reino de Chile a su independencia, y la pronta conouista obreda en él for las armas de la patria. que con un tercio de fuerzas venciercn a las tropas de Esfaña y a sus jeles anguerridos con los franceses, maniliesta lo que debe esperarse de los esiuerzos patrióticos..| Dejemos al tiempo el descubrir la explosión gue necesariamente ha de causar la tiranía en Lima, y todo el Perú. ¡Qué no pueden las angustias de la hartbre 
Fué después de la victoria de Chacabuco que las comunicaciones entre San Martín y los revolucionarios limeños se formalizaron, y estas comunicaciones sugirieron a San Martín, —dice Mitre- la idea de realizar en e! Perú otra "guerra de zapa", igual a la que había realizado en Chile, descie Mendoza, preparando al país para la invasión y que tan buenos resultádos le dió. "En 1817 Riva Acrüero hizo llegar a manos de San Martín varios informes relacionados con la invasión de! Perí. El documiento que los contiene es interesante: "Para posesionarse del Perú. le dice Riva Agüero a San Martín, se necesita muy poco, peraue la voiuntad general es decisiva a favor de la unión de Chile con Bienos Aires, lo que verificado que sea, es inconquistable la Anér:ca de! Sur por "as potencias de Europa". Las fuerzas para esta empresa por parte de las Provincias Unidas y de Chile, deben componerse de sezún él, de quinientos hombres, pero deberán traer convigo ermamentos para sieto mil. Desembarcadas estas fuerzas, se les reunirán las provinc:as de A.squipa, Cuzco, Puno. Estas fuerzas comandadas por San Martín, y las de Belgrano atacarían simultánoamente al Ejército de La Serná y la escuadra bloquearía el puerto del Callao. En caso ele alve el ésrdito libertador del Perú sé compusiese de siete riil hombres podía desembarcar en las inmediaciones de Pisco. De allí se distribuirían sue prociamas, y provisto de cabalgaduras y engrosado con las milicias peruanas que vendrían a su encuentro, podía caer sobre la capita. Lipho que se fectuaba otro desembarco en Huacho". (9).

Riva Agüsro on sus Menorias se refiere a que varias veces envió a Chile el pian de camparan cále debía de seguir la expedición libertaderà del Ferid. "frada fay por cierto, más violento para mi, que verme oblisado a indicar tal o cual servicio hecho a la causa de la independencia de ril Patria, pero por mús que me repugne hablar de ni mismo, me voo en la resesidad absoluta de referir en esta nota, que el plan da campaña para la expedición liberiadora del Perú, así como los reflexiores a śl conexas, lo remití al gobierno de Chile

ciovorodoral ¿Y cuál ro sorá al gozo de estos habilantes cuando se les aparezca un ejército $y$ escuzdia de sis hormanos de! Río de la flata a redimirlos do tantas y ten terrikles cánidedes?. Sin duda que entonces será el término de todos los crímsnes y el prineipio da la felicidad conín".- "El famoso y ya rarisimo bolle10 enónimc de Fiva Agülero socre "Las 28 causas" de la Revolución de América".E. Boletin del Muses Eolivariano".- Año Il.- No 14.- Pág. 60 y 61.

(9) "Historie del Libcrtader con Iosś de San Martín".- Por José Pacífico Otero, Buenos Afres, 1949.- Tons III, Fíg. 24. 
en distintas ocasiones. Una de estas comunicaciones la condujo a Chile don Francisco Caldera, otra don Joaguín de Echevarría y Larraín, ministro de Estado que ha sido después en esa República; y el triplicado don Antonio Alvarez Jonte (10)... En todas estas comunicaciones, y después de contestaciones diversas con Alvarez Jonte, acerca del plan de campaña, fuí yo el que más insté para que se røalizase la expedición, demostrando los resultados que tuvo. Otras varias comunicaciones, remití por los buques ingleses y anglo-americanos. También fué a Chile don Remigio Silva con el objeto de instar de mi parte la pronta venida de la expedición. No solamente puse lo concerniente al plàn de campaña, sino que me extendí a cuanto creía conveniente formar la opinićn pública de los peruanos, remitiendo antes un gran número de manuscritos para que en Buenos Aires y en Chile se imprimiesen; llegando a tanto mi menudencia, que con el referido señor Echevarría acompañé hasta los puntos de la proclama a los pueblos del Perú, que se imprimio en Santiago a nombre del general que mandaba la expedición". (11).

Por supuesto que no es creíble que San Martín utilizara ampliamente los planes mandados por Riva Ágüero y los siguiera al pie de la letra, pero es indudable que te sirvieron de mucho para elaborar su plan de campaña definitivo.

Uno de estos correos tenidos entre San Martín y Rivä Agtiero, y que eran traídos poB labescuadracde Cochrane quegmerodeaba consiantemente desde 1818 "en las costas peruamas por los buques mercantes ingleses y norteamericanos que al amparo de una amable neutralidad traían espías, fué apresado por los soldados de Pezuela a la altura de Supe. Se trataba del Clérigo don Cayetano Requena (12) que iba a caballo con un negro, conduciendo correspondencia recién desembarcada por Alvarez Jonte para Riva Agüero y su círculo, dándoles noti-

(10) Secretario del Vice-Almirante Cochrane, y agente de San Martín.

(11) "Memoria dirigida desde Amberes al Congreso del Perú", por José de la Riva Agüero.- Santiago de Chile, 1828, págs. 50.55.

Mitro en su "Historia de San Martín". cap. XXV, se refiere a la llegada de Silvia a Chile con un plan para invardir el Perú: "consistía en efectuar un doble desembarco al sur $y$ al norte de lima con dos divisiones de 2.500 a 3.000 hombres cada una $\mathrm{y}$ converger sobre ella, mientras la escuadra amagaba un desembarco por el Callao".

(12) Requena había sido Maestre Escuela de Lima; cancelario de la Universidad de San Marcos; teniente del Vicaric oeneral del Ejército. Se había pasado entonces a les filas revolucionarias. En 1812 formó parte del primer Congreso peruano como represeritanie por el Departamento de la Costa (norle de Lima). 


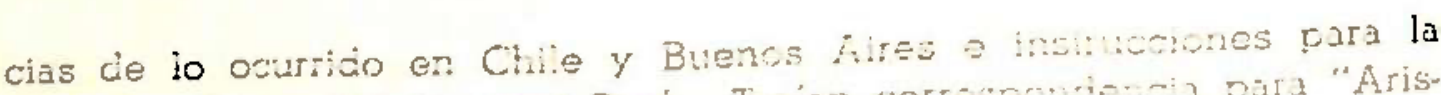
obra que desarollaben e. el Peá. Traian corrempondoncia para "Aristipo Emero" y oiros rerolucicharios peruanos nomitados con selionimo, que la historia hesta el presente isno:e quisnes horon. (13). Como consecuencia de esta caplura, fiva Aguero ili p poso y comendo a juí-

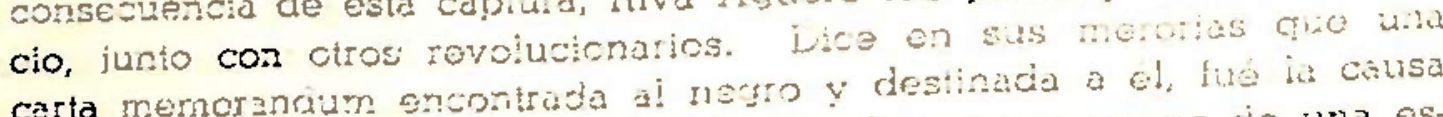

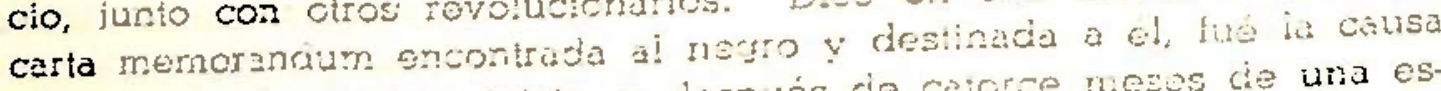
para que se le siguiera juicio, $y$ despues do caiorce mezes he una estrecha e inctinosia prisicn en continua incomunicacicin en Turna, se pi

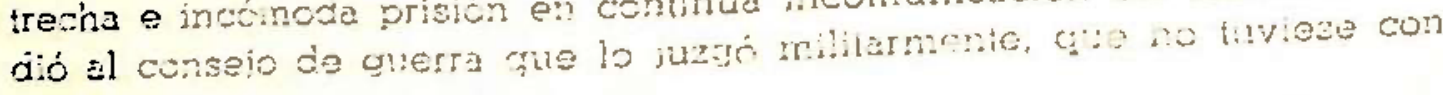

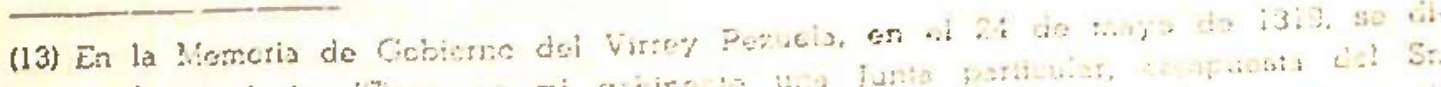

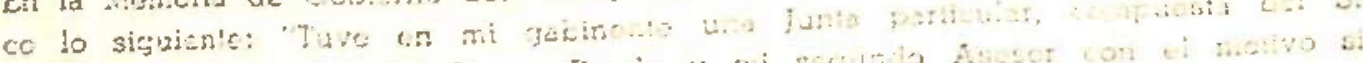

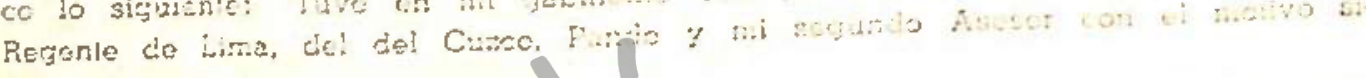
guiente:

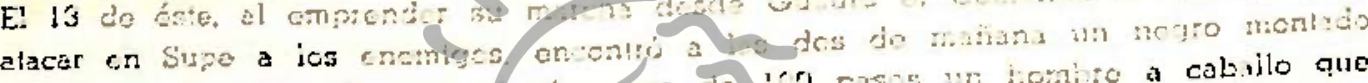

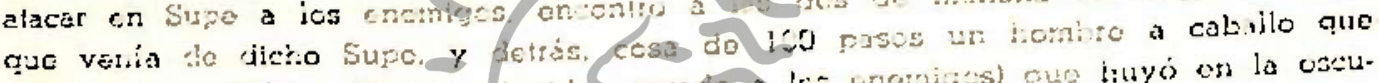

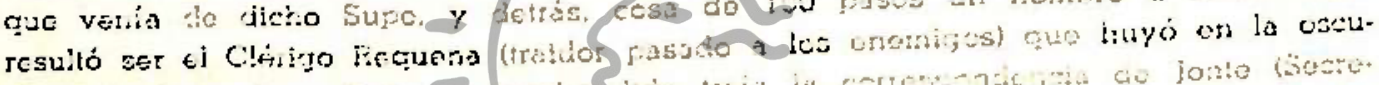

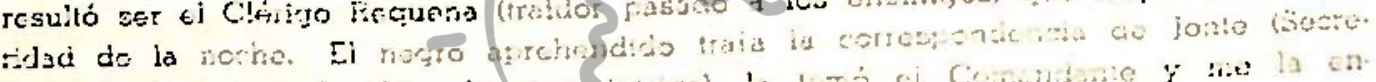

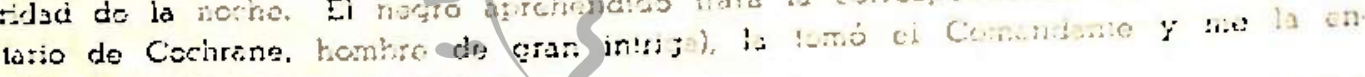
vió resultonjo ser iz sizuirnte:

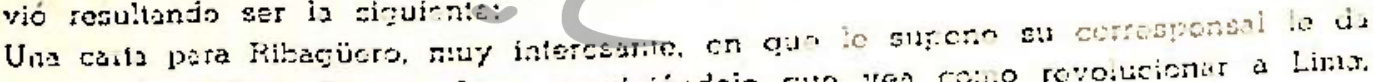

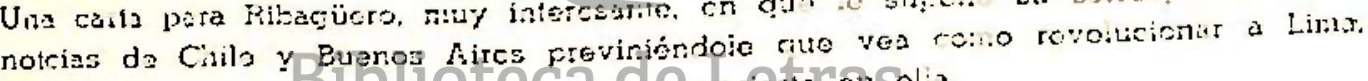

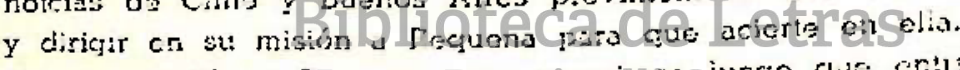

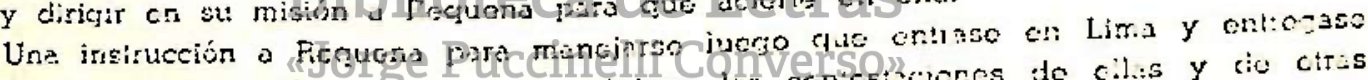

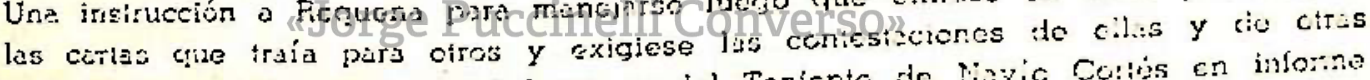

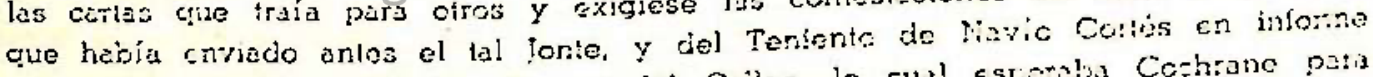
que habia efrociclo sobre los fuerzas det Calleo. to end esporalsa Cachrane patia sus operacicnes sobre of puerio y pera tue froporcionase aixilio is la coraspon. dencia cue tenía po: Chorillos y linalmento, h lal corresponden ía era un conpendio del estado dé los enemiges y una marifestecion do los britons sue hay en esta capital.

Ambos Regentes, impuestos de todo, opinaron que convendria oír al Sr. Sub-Inspeclor General y con efecto, cité para otra día, cn cue rcunides les tres a mi presencia, opinaron quo:

Riva-Agüero y Corlés saliesen, con cualquier prelexlo de la ciudad. interim se proporcionzía barco para la Península.

El supuesto don Arislipo Emero, para quien vino una carta: que se do una al Administracor de Correos con tal nombre para ceger al que vaya a sacarla. Que el Gobierno esté a la mira de éstos por lener la más bien sentada opinión:

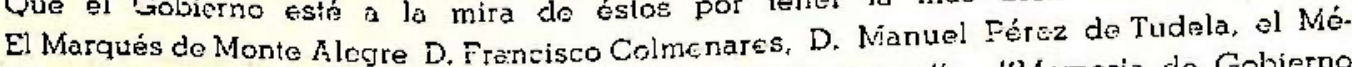
dico Pezel, D. Francisco Campino Zaldaña, Velasco, San Roque". - "Míemoria do Gobierno del Virrey Pezuela".- Edición de Vicente Rodríguez Casado y Guillermo Lohmann Villena.- Sevilla, 1947.- Pógs. 464-65. 
él ninguia indulgencia, sino que procediese a condenarle a muerte $y$ que iniugrcsamente salvó la vida debido a la influencias de que gozaba. (14).

A fines de 1917, siguiendo la táctica que tan buenos resultados le había ciado en la invasión de Chile, envió ante el Virrey Pezuela, con el pretexio de paciar el canje de prisioneros, así como antes, desde Mondoza, lo nabía hecho con el Capitán general de Chile Marcó del Font, un errisario suyo. El objeto de esta misión no era sino enterarse de! estacio políico y militar de Lima, tomar razón de las fuerzas marítinas y ierrestres que guarnecín el Porú, así como el número y caliclaj de sus bugues de guerra y armàmento, indagar las opiniones de sus jeíes y oficinles, y poierse en comunicación con los patriotas más señalacios.

El comisionacio llegó al Callao a bordo de la fragata de guerra inglesa "Anfión", el i2 de mayo de 1817. y su comandante, el Comodoro D. Guillermo Bowles, le hizo llegar al Virrey una comunicación de San Niartir en que le avisába el envio a bordo de ella del Sargento Mayor don Doningo Torres, en clase de parlamentario, con la misión de pactär un cunje de prisioneros. Al Virrey, según anota en su Memoria (15), le causó sorpresa Y le pareció muy sospechosa tal misión en los momentos en quie estaba preparando la expedición contra Chile al mando del general Osorio, y procedió con especial cautela. Puso como condición al Corrcdoro Bowrles, Cquele talparlamentario no permaneciera a bordo, sino «ẹn el Callaoi hajoi suocustodia, hasta que la expedición a Chile saliera del puerto. La condición fué aceptada y Torres permeneció en el Callao, con bastante custodia, hasta el 19 de diciembre ein cue voivió a bordo de la "Anfićn" y regresó a Chile con una carta pariiculer de Pezlela a San Mártín en que aceptaba, con ciertas con. diciones, el canje de prisioneros.

Apenas llegado el parlamentario, los revolucionarios limeños buscaron la manera de comunicarse con él, y ya fuera de palabra o por escrito, le hicieron llegar los informes que necesitaba. "Consistían éstos en esiados exactos del número de tropas rue entonces guarnecían el Virrenato y las armas que existían en sus arsenales, razones de sus buques armados, listas de los corresponsales de quienes los invasores. podian valerse en las comunicaciones en la costa, clasificaciones númericas de los patriotas existentes en Lima, y por último, claves secre-

(14) "Merforia dirigida desde Amberes al Conoreso del Perú".-Cit., páog. 50.

(15) "Memoria de Goheino del Virrey Pezucla".- Cit., págs. 183-84 y 200. 
tas para combinar sus correspondencias. Riva Arüiero dictuba éstas, el oficial de marina Carrazco trabajeba agueilos pianos, Quiróa y el patricta Menéndez, procuraban en las offcinas mismes de gojierno los dato3 oficiales, el coronel Bernales, prófugo de Casas Matas, como después veremos, daba avisos desde Supe, donde se hübia refugiado, sobre las combinaciones que podian establecerse en la Costa abajo, Y por último, el modesto y laborioso figuetos, se osupaba en la redacción de todas aquellas plezas, oficio a que era destinado por su excelente letra, no menos que por su probada circunspección, y éste se encargaba edemás de hacerla llegar hasla Torres por conducto de su antigua amiga y favorecedora desde 1809, la señora Silva. La última remesa de papeles que se hizo a Torres al regresar a Chile, le fué entregada a bordo ciel buque que le transportaba a Valparaíso, por el mismo Figueroa y Quirós, quienes hicieron expresamente un viaje nocturno y a pie al Callao para burlar la vigilancia de las rondas de la bahía. La propia muier de Quiróz llevó ocultas en su viaje aquellas arriesgadas y esenciales comunicaciones"? (16). También se le entregaron a Torres datos recogidos de la misma secretaria del Virrey sobre la expedición que había zarpado para Chile, así como su plan de campaña. Torres logró llegar antes de la Expedición de Osorio, y San Martín, pudo así prepararse, y destrozarla finalmente en los campos de Maipú.

A principios de 1819 , encontrándose el general San Martín en el momento crusial de cbnsegufrcblapoyoldeechile y Argentina para realizar su expedición al Perú, envió a dos emisarios suyos, los peruanos José Fernando Paredes y José García para llenar una delicada misión, dánjoles instrucciones precisas y detalladas. El $1^{\circ}$ de enero les dió dichas instrucciones, y por ellas se impusieron que debían tomar conocimiento de todos los recursos pecuniarios del gobierno de Lima, del estado de su tropa, número, calidad y disciplina; conocer cuál era el plen de operaciones del Virrey en caso de que Lima fuera atacadā; porqué parte de la costa se temía el desembarco; quje se informaran quiénes ezan los favoritos del Virrey, cuáles los oficiales de mayor opinión; quiénes eran los espías favoritos de Pezuela en Chile y Buenos Aires, informarse sobre las relaciones secretas de Pezuela, sus vicios públicos y su conducta privada; saber si habían algumas dāmas que tenían ascendiente sobre él; quiénes eran y cuáles las relaciones con estas da. mas; cuál era la opinión del clero y de los religiosos en general, curas

(16) Vicuña Meckenna.- Ob. clt., pág. 174. 
y monjas; cuál la opinión del Cablido Eclesiástico, y si era amigo o enemigo de los patriotas. Debían de sembrar la discordia entre los españoles, jefes y amigos de Pezuela y que además de usar la intriga impresa convenía usar la sátira y el ridículo. Declaraba además que toda medida violenta era sin duda peligrosa, pero que si se hacía necesario era sabio el usarla. Los facultaba para hacer uso franco de su firma para exigir a los revolucoinarios peruanos dinero suficiente para el cumplimiento de su misión, y que la correspondencia que recibirían estaría con nombres figurados, a saber: a Paredes el de Casio y a García el de Mario. (17).

El 13 de enero de 1819 se embarcaron en Valparaíso en la escuadra de Cochrane, y pocos días después desembarcaban de noche en la playa de Āncón, enterrando en la arena un cajón con prcclamas y otros documentos, y dirigiéndose a Lima. Sus primeras acciones estuvieron destinadas a ponerse en contacto con el grupo de revolucionarios limeños, especialmente con Riva Agüero, para quienes traían correspondencia especial de San Martín. Luego se enviaron a varias personas para que desenterraran de la playa de Ancón el cajón de impresos que habían traído. Llenada su misión en Lima, y después de haber recibido dinero suficiente recolectado entre los patriotas, ambos se dirigieron hacia el interior para cumplir la otra fase de su misión. Don José Paredes se dirigió a la región de Huaylas, en cuyo viaje le acompañó don José María Ochoa, el mismo que había sido comisionado para que sacara largorrespondencia ynlaecondujera a Lima. García se dirigió por la costa hacia Trujillo. En Huaylas, Paredes cumplió fielmente su misión, dando curso a lac cartas de que era.portador y sembrando su camino de proclamas y papeles revolucoinarios. De rgreso a Lima, se einbarcó luego para Chile con los datos proporcionados por los revolucionarios limeños, mereciendo honores y distinciones de San Martín.

Harto diferente fué en cambio la acción de García. Detenido en el pueblo de Huarmey por un destacamento realista, traicionó a sus amigos delatándolos al Virrey con el objeto de salvarse y de apoderarse del dinero que le habían dado en Lima. El 31 de de diciembre de 1819 fué apresado. El Virrey ordenó que se le siguiera causa el Regente Pardo y comisionó al Teniente Coronel de artillería don Fernando Cacho para que le tomara las correspondientes declaraciones. (18)..

(17) José P. Otero.- Ob. cit., págs. 20-22.

(18) "Memorias de Gobierno del Virrey Pezuela", cit., págs. 590-93. 
Debido a la cleclaración de García, fueron apresados el Lunes Santo, 26 de marzo de 1850, Riva Agüero y Ios demás comprometidos.

El documento de la declaración de Garcia ha sido publicado recientemente (19). En él consta que trajeron cartas para el Padre Carrión de San Pedro, el Cura Tagle, don Gerónino Espinosa, don Diego Aliaga, don José Pezet, el Conde de la Vega, don Hipólito Unánue, don Gaspar Rico y otros más, pues lás cartas eran, dice, doce o catcrce. Algunas de estas carias las entregaron personalmente y otras quedaron en poder de Riva Aqüero que era quien las distribuía. Menciona como sitios de reuniones a un Tambo en la Calle de Malambo, la casa de Riva Agüero, la de don Mateo Aranda, la casa de un tal Castro, una casa en la calle Baquíjano, otra en la calle la Rifa, y señala como conspiradores a don Mateo Aranda, el coronel Bernales, Castro, Riquero, don Joaquin Mansilla, don Pedro Rodríguez, don Manuel Fonseca, don Domingo Aranda, Canza, Remigio Silva, Mansil!a Rodríguez, los curas Echague, Pedro de la Hoz, Rosel y Guapaya; don Diego Aliaga, el Conde la Vega, y luego menciona a muchas personas en provincias que actuaban como agentes revolucionarios. De esta declaración se desprendía que Riva Agüero era el principal promotor de la labor revolucionario. El, y don Gerónimo Espinosa habían sido los principales en aportar dinero en vista de libranzas firmadas por San Martín. En una parte de su declaración acusó de que "Riva Agüero y Castro han dado a Say Martín noticiás individuales de todo, hasta de lo que se hablabalengeel gabineteldepecmop"Sr. Virrey y le han ofrecido que el pueblo de Lima $y$ de las provincias se alborotaría inmediatamente que se presentaran".

La labor revolucionaria, pues crecía todo poderosa, a medida que se acercaba la fecha crucial de la invasión libertadora. "Es notorio, dice Riva Agüero, que fuí yo el primero que, valiéndome de persuaciones y de cuantos medios me fueron posibles, introduje la deserción entre los oficiales y la tropa del ejército del Rey. Lo es igualmente, que para que esto se verificase, hice considerables gastos; que introduje agentes y apologistas de la revolución hasta en las casas particulares, y en el centro mismo de los cuerpos que sostenían el absolutismo. Es también sabido que muchos que desertaban de las banderas españolas eran encaminados por mis agentes por sendas extraviadas hasta incorporarse a las guerrillas, refugiándose muchos en mi chá-

(19) En "Mar del Sur", No 12, Julio-Agosto de 1950.- Publicado por José Agustín de la Puente y Candamo y Luis Jaime Cisneros. 
cara hasía ser habilitados y conducidos sin riesgo; todo esto sin perjuicio de los desemicolsos para auxiliar a muchas personas perseguidas por su pairiotismo. Es asimismo notorio lo que costaron a mis intereses los emisarios Paredes y García, y el perjuicio que me causó éste denunciándome inícuamente al gobierno español, tal vez con el objeto de convertir en propiedad suya, las considerables sumas que le di, y las que coniribuyeron otros patriotas con vista de una credencial, en que al genera' San Martín los autorizaba para que tomaran dinero de los patícias. Lo cierto es que yo fui sacrificado de todos modos; y mis riesgos pueden verse en la causa que se me siguió por el coronel Cacho, íiscal de ella". (20).

La correspondencia entre los patriotas peruanos y San Martín fué numerosa entre les eños 1819 y 1820 . La escuatdra de Cochrane, que constantemente merodeaba por las costas peruanas y los buques ingleses y norteamericanos que amparaban discretamente a los revolucionarios, eran los portadores de la correspondencia. Espías colocados a lo largo de la cosia y en sitios ce antemano convenidos servían de enlace entre los revolucionarios y los buques. Señales establecidas hacían saber si era o no posible el desembarco: "Una bandera blanca con celeste - dice el espía García en declaración- puesta en una altura quiere decir que hay correspondencia al pie del asta, o que se pide el bote a tierra; si la bandera está caida quiere decir que sacaron la correspondencia; si enrollada, que no hay contesto y que no aguarde; si es azul que pasan jumediatass cargasool corroosin custodia, si entonces enrollan la bandera quiere decir que esa noche bajan a tierra; si la bandera es colorada, quiere decir que hay tropas inmediatas y está mala la inmediación".

Mucha de esta correspondencia estaba en clave o firmada con seudónimos o numerada. "La historia nos ha revelado la personalidad de algunos de ellos y sabemos así que Riva Agüero, se ocultaba tras el seudónimo de Paciencia o de Lemóstenes, que Joaquín Campiño y Fernando López Aldana se asociaban en la misma comunidad nominativa y firmaban con el seudónimo de José Pardo Prieto y Cía.; pero ignoramos quién era Caupolicán, perosanje que inicia su correspondencia con San Martín llenando sus líneas con los signos del ritualismo masónico, y quién igualmente Philadelpho y quiénAristipo Emero, celoso e inteligente colaborador. Algunos de los corresponsales de San Martín firmaban con sus cifras, y Paz Soldán, que nos da a conocer

(20) "Memoria escrita desde Amberes al Congreso del Perú".- Cit. pág. 53. 
parte de la clave usada por los revolucoinarios; nos dice asi por ejemplo, que el 1EO correspondía a García del Río, el 456 a Porto Carre ro, y el 33 a Juan de Dios Ariza". (21). Oiro seudónimo cmpleado fué el de "Señor el Soldado".

Aristipo Emero, el gran conspirador cilya identilicación ignoramos, le proporcionó a San Marín muy valiosos informes. En su comunicación de fecha 16 de marzo de 1819, le inf́crmaba que la ciudad de Lima estaba desmantelada y sin preparativo alguno para la delensa; que se temía un desembarco por pusrios iniernedios o Pisco y que por allí estaba Ricafort con dos mil soldados y en Lima el mariscal Gonzáles con mil milicianos: En el Callao existian dos mil hombres $y$ el Virrey hasía convozado a una Junta para tratar de! acuartelamiento. Le desía cure Fezucla hadía resuelto salir al campo de batalla y que haíía nombrado al marqués do Montemira, Gobernador de la Capital y le daba razón de los lavoritos de! Virrey. Le dice que los europeos pudientes habían remitido porte de sus caudales a España y que se ocultaba mucho dinero en los conventos de frailes y monjas y en algunos pueblos de las inmediaciones de la ciudad, que el Arzobispo era un realista tenez. En olra ccmunización le dice que se teme que el desembarco se haga por Pisco o por alguno de los puertos intermedios; que muy pocos creen que se electúe por el Callao o sus inmediaciones; que más biem piensan que se haga por Chancay y que están artillando esa zona Señala las personas adictas a la causa de la independencia, "entre los que sobresale el SRecior de la Universidad de San Marcos, José Caberoz y Salazar y dice que entre los sesenta abogados de Lima, habrá diez que son contrarios a al libertad. (22).

En una proclama anónima, escrita en Jima y dirigida a los habitantes de Chile, se decía lo siguiente: "Se necesita para un sacudimiento el impulso y la acción de una mano fuerte y diestra que venga de afuera, a la cual no sólo no resistirán los peruanos, pues là desean con ansia, sino que la recibirán con gusto, porque conocen las necesidades de ella para escapar del yugo opresor y sus cadenas... No hay sino que venir a redimirnos, a darnos impulso con vuestras tropas y armas. Vuestra presencia elecirizará a los patrictas y abatirá el orgullo de los déspotas. ¡Expediciónl ¡Expedición!. Esto es lo que clama el Perú todo y esto es lo único que a la América del Sur conviene".

(21) José P. Otero- Ob. cit., pég. 23-24.

(22) Otero.- Ob. cit., págs. 24-28. 
El Virrey Pezuela no ignoraba esta correspondencia entre San Martín y los revohucionarios peruanos y extremsa la vigilancla y las medidas represivas para contenerla, ya que no podía hacerla desaparecer. Por su parte, ol Virrey no ignoraba los pormenores de los preparativos que hacía San Marlín en Chile, en donde tenía espías, y sabía que de un momento a otro tendría que habérselas con el ejército expedicionario. Por lo derrás, las acciones de Cochrane en la costa lo mantenían en un estado de permanente irquetud. Así el 2 de abril de 1819 recibió noticia de que habían desembarcado en Huacho a fines de febrero, de 400 a 500 hombres, los cuales sa habian apoderado momentáneamente del valle de Huaura, en donde con la ayuda de la población se apoderaron de viveres y ganado y a la vez que distribuían proclamas revolucionarias. El Virrey despachó tropas a su encuentro, pero cuando liegaron al teatro de los sucesos, los insurgentes se habían embarcado. En Supe los revolucicnarios hábían sijo jubilosamente recibidos por el puehlo en Cabildo $\Lambda$ bierto. A fines de abril la escuadra estuvo merodeando entre Calleo y Chorrillos, manteniendo a sus buques en estado de alerta. A princióos de mayo recibió notisia de que habían vuelto a desembarcar en Supe. El comardante Cucalón encargado de hacerles frente tivo con ollos una escaramusa, y después de media hora de pelea se vió cbligado a ræplegarze a Huaura con 5 rnuertos, 6 heridos y 5 extraviados. A fines de mayo desembarcaron en Huarmey. El 18 de junio desembercaron en Casma en busca de víveres y so áboderaron de una Tancha cañonsa ded. Rey, haciendo 9 prisioneros. A fines de setiembre luvo noticia de haberse desembarcado espials en Huarfifey, envando tépa"en su busca. El 28 del mismo mes Cochrane se presentó en el Callao. A principios de noviembre, Cochrane volvió a aparecer entre el Cana y Pisco y a fines de dicho mes recibió noticia de que el Vice-Almiranie se encontraba por los puertos de la costa norte. A principios de enero de 1820 supo de que se anunciaba la salida de la expedición de Chile hacia las costas de Arequipa para dentro de dos meses. En mayo recibió noticia de que se había cerrado el puerio de Vấperáso, presumiendo de que se tratraba de los preparativos de la partida de la expedición. En junio fué informado de que se había atacado el puerto de Arica. En julio llegó a sus manos una proclama de San Martín dirigida a su ejército en Chile, anunciándoles la próxima partida de la expedición al Perú. En agosto fueron apresados el teniente José Barrenechea, Federico Bergman y cuatro marineros más que habían desembarcado en 
día 9 más abajo de Pativilca junto con otros espius, paro habiendo zozobrado la lancha, quedaron en la playa sisndo aprejucios mientras otros legraron escapar. (23).

En agosto de 1820, en momentos er qus San Martín siguiendo el destino que lo llamaba se háta puesto en marchí coi: su Expedicićn Libertadora hacia las costas de! rnás pojeroso Virre:nuto de América española, nuestro país esiaba moraimente revolucionedo por obra suya y de sus propios htjos, y esperaba ver aparecer de un momento a otro la tan annelada exosdicín. Pura dir una idea de la eficacia de la labor realizada, transcribimos lo que dice Pezuela en sus Memorias, el día 3 de seiteinbre de 1920 . "Me ertregr el Procurador Ulloa una porción de Proclarnas, introducidas en esta Capital y entregadas a su muger (sic) por una persona desconccida, dirigidas, la una a los soldados Americanos del Exto. del Virrey en Lima, ctra a los soldados españoles del mismo Exto., oira a los habitantes del Perú; otra a los españolss europeos recidentes en el Perú, otra a la Nobleza Peruana, y otra a' bello Sexo. Las einco primeras firmadas por el general enemigo San Martín y la 6a. por un Americaro, como se ve en las originales que se hallan en el Quaderno (sic) $9^{*}$ Copiador. Las firmadas por San Martín se supone que ya ha desembarcado su Expedición en ntras. Costas, pues que habla desde ellas".

"La facilidad con que han sido introducidas en esta Capital las expresadas Proclamas manifiesta bien claramente que los Enemigos tienen en ella $y$ en la Costa Qugefos (sic) segurostde que valerse, y de consiguiente, enemigósinteiloresidel lá causae deb "Rey".

"Inmediatamente despachó una circular a los Comandantes Militares de todos los puestos de la Costa é intendentes de las Provincias interiores con exemplar de dichas Proclamas, a fin de que estubiesen (sic) prevenidos para interceptarlas $y$ advertir a los soldados $y$ habitantes de que no se dexasen seducir".

Pero todo fué en vano. El 10 de setiembre recibió noticia de que en Pisco había desembarcado la Expedición Libertadora en número de 4.000 hombres. La bandera de la Libertad había sido plantada en nuestras playas por obra de San Martín. La guerra por la independencia de América española entraba en su fase definitiva.

(23) Memoria de Gobierno del Virrey Pezuela".- Cit., Págs. 427, 432, 433, 441, 454, $469,476,522,526,532,553,556,558,566,570,631,634,637,675,725,732,738$, $745,747$.

(24) Memoria.- Cit., págs. 753.54 . 